\title{
COSTAL CARTILAGES - A CLUE FOR DETERMINATION OF SEX
}

\author{
Olga Rejtarováa, Dáša Sližováa, Pavel Šmoranc ${ }^{b}$, Pavel Rejtar ${ }^{b}$, Josef Bukačc
}

\author{
a Department of Anatomy, Charles University in Prague, Faculty of Medicine in Hradec Králové \\ ${ }^{b}$ Department of Radiology, Charles University Hospital in Hradec Králové \\ - Department of Statistics, Charles University in Prague, Faculty of Medicine in Hradec Králové, Czech Republic \\ e-mail: rejto@lfhk.cuni.cz
}

Received: September 20, 2004

Key words: Costal cartilage/Calcification/Rib/Sex

Mineralization and ossification in the human costal cartilages were studied radiologically. The aim of our study was to evaluate differences between males and females with respect

to patterns of costal cartilage calcification and also with respect to ageing.

Material for this study consists of 1044 chest and abdominal radiograms of the Czech population from the Department of Radiology (537 males and 507 females).

Further radiograms of 18 chest plates were obtained at routine necropsy of cadavers.

The radiograms were examined for pattern of ossification of the costal cartilage. The first rib cartilages were not considered because there are no sex differences.

The lower ribs exhibit sexual dimorphism. Mineralization and ossification changes appear at the end of puberty and their occurrence increases with age. The sexual difference in pattern of human costal cartilages is statistically significant and thus highly predictive of sex determination.

\section{INTRODUCTION}

The costal cartilages are invisible in the radiograms unless they are calcified. Calcification and ossification are the main changes which appear in ageing costal cartilages. Previous studies have attempted to correlate costal cartilage calcification with many pathological states, e.g. arteriosclerosis, nutritional state, metabolic or endocrine changes $^{4,6}$. Genetic influences are also mentioned ${ }^{9}$. Differences between males and females in costal cartilage calcification were first described in $1955^{3}$. Later, other authors $1,2,7,8,10$ described the differences in their studies.

The aim of this study was to evaluate the occurrence of costal ossification and to compare ossification patterns in men and women.

\section{MATERIALS AND METHODS}

Frontal chest and abdominal radiograms of patients, ranging in age from 10 to 95 years which were acquired at the Department of Radiology, Charles University Hospital in Hradec Králové in the period 1995-2003 were used. A total of 1044 radiograms (537 men and 507 women) were randomly selected. The first rib was ignored, since sexual differences in patterns of costal cartilage calcification have not been found ${ }^{5}$. Ossification changes of the other ribs were divided into 4 groups.
A. Type I. - peripheral pattern (P), characterized by ossification of the inferior and superior costal cartilage margin,

B. Type II.
a) - central lingual pattern $(\mathbf{C l})$, characterized by pyramidal-shaped central tongues of ossification beginning in the fossae costarum,
b) - central globular pattern ( $\mathbf{C g})$, consisting of centrally-placed, smoothly-contoured globules of ossification,
c) - central lingual and globular pattern (Clg),

C. Type III - mixed (peripheral and central) pattern (Mix),

D. Type IV - indifferent pattern (Ind) - incipient calcification without differentiation into sex specific pattern.

During autopsy in the Department of Anatomy 7 chest plates, consisting of the terminal $4-6 \mathrm{~cm}$ of the ribs, the costal cartilages and the sternum were removed and radiographed. Next 11 fragments of chest plates from cadavers dissected in the Department of Forensic Medicine were radiographed, too. Costal cartilages of 5 fragments were cut into $3-5 \mathrm{~mm}$ thick pieces and examined using a mammographic technique. 


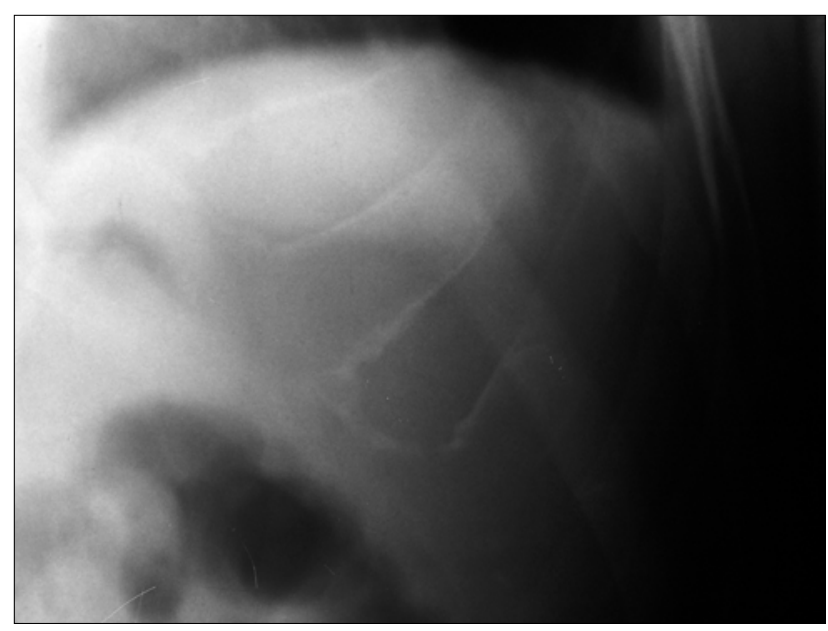

Fig. 1. Peripheral type of ossification. 81 years old man (clinical radiogram)

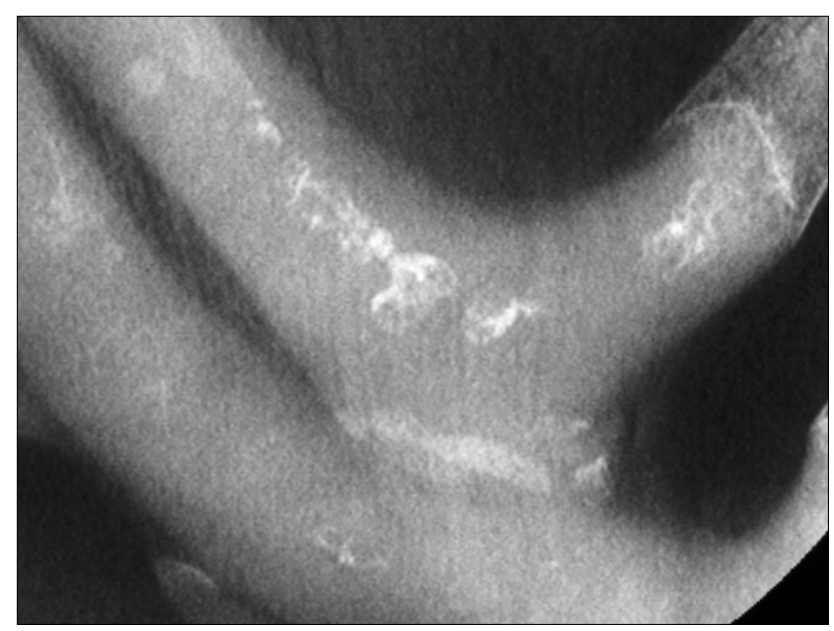

Fig. 2. Central lingual and globular type of ossification. 64 years old woman (radiogram of cadaverous material)

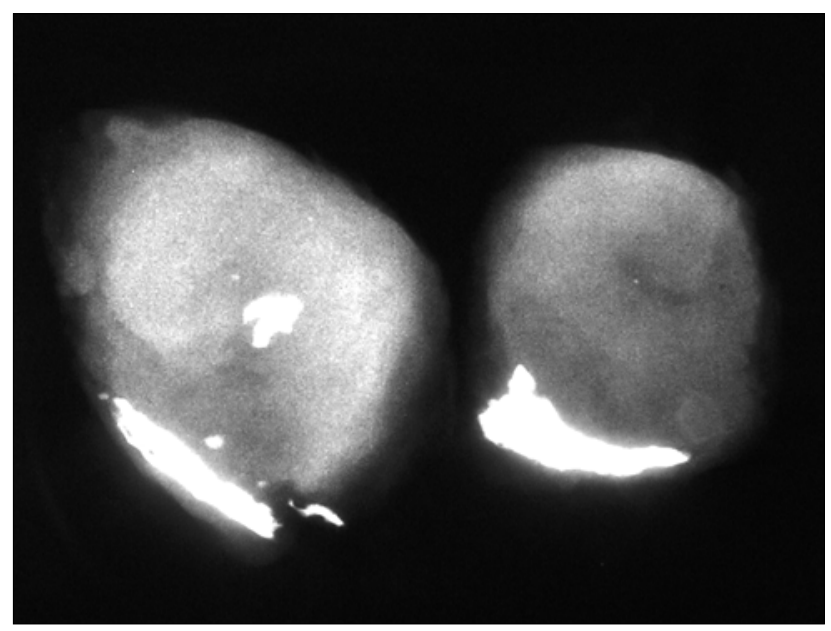

Fig. 3. Mixed type of ossification (central and peripheral). 64 years old man (radiogram of transversal section through costal cartilage of cadaver)

\section{RESULTS AND DISCUSSION}

We examined 1044 chest and abdomen radiograms. Mineralization changes were found in 538 cases (52\%). The group of positive findings contains all types of pattern. The collection of positive women contains $77 \%$ of central patterns, the collection of positive men contains $93 \%$ of peripheral patterns.

Table 1. A complete breakdown of all patterns of ossification in males and females in absolute numbers.

\begin{tabular}{|l|r|r|r|r|r|r|}
\hline Pattern & \multicolumn{1}{|c|}{ Neg } & \multicolumn{1}{c|}{ Ind } & \multicolumn{1}{c|}{ P } & \multicolumn{1}{c|}{ C } & C+P & Total \\
\hline Males & 269 & 15 & 249 & 0 & 4 & 537 \\
\hline Females & 247 & 35 & 1 & 201 & 23 & 507 \\
\hline Total & 516 & 50 & 250 & 201 & 27 & 1044 \\
\hline
\end{tabular}

The occurrence of ossification types in our collection is shown in Fig. 4. The relationship between age and positive ossification findings in men and women is shown in Fig. 5.

Central ossification pattern appears in 3 subgroups - central lingual $(\mathrm{Cl})$, central globular $(\mathrm{Cg})$ and central lingual and globular $(\mathrm{Clg})$.

Table 2. Percentage of occurrence of type subgroups in female population.

\begin{tabular}{|l|c|c|c|c|}
\hline Pattern & Cl & Cg & Cl+g & Total \\
\hline Females & $\begin{array}{c}114 \\
(57 \%)\end{array}$ & $\begin{array}{c}47 \\
(23 \%)\end{array}$ & $\begin{array}{c}40 \\
(20 \%)\end{array}$ & $\begin{array}{c}201 \\
(100 \%)\end{array}$ \\
\hline
\end{tabular}

Ossifications of the costal cartilages generally increase with the age. In the collection of 18 cadaver radiograms ( 6 women and 12 men), we also examined types of ossification. We found central types of ossification in women, peripheral or mixed types in 11 men, and central lingual and globular type of ossification in one man.

The data in the Tab. 1 suggest that the sex can be predicted with considerable accuracy from the patterns of ossification of rib cartilages. The accuracy of this appraisal was assessed by estimating the statistic probability. The finding of a peripheral type of ossification determines male sex with $99,6 \%$ probability, the central type of ossification determines female sex with $100 \%$ probability.

Using a simple, rapid and cheap method, our study suggests the existence of sexually dimorphic patterns of human costal cartilages. The classification of ossification patterns can also help with estimation of age in many cases, especially in women. 


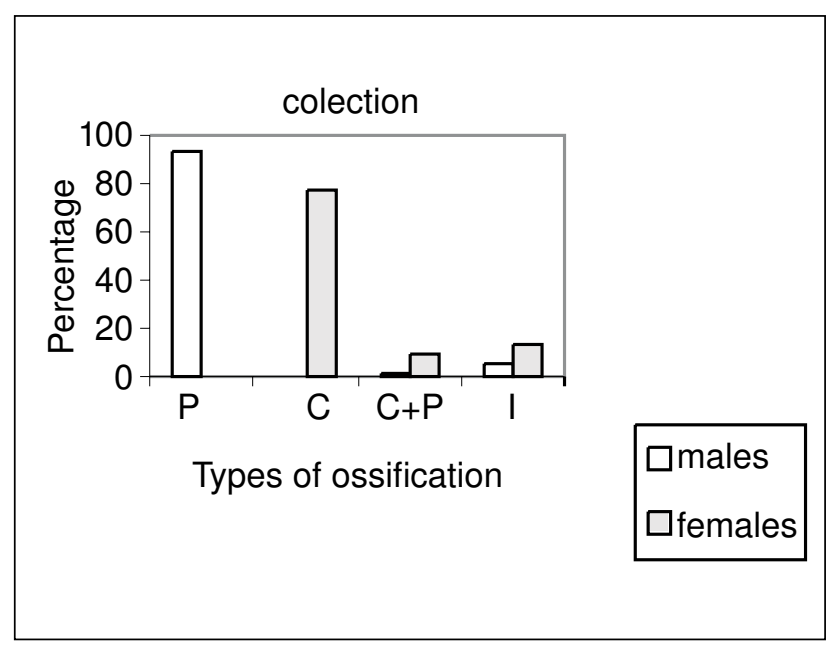

Fig. 4. The occurence of ossification types.

\section{REFERENCES}

1. Elkeles A. (1996) Sex differences in the calcification of the costal cartilage. J Am Geriatr Soc 14, 456-62.

2. Felson B. Chest Roentgenology. Philadelphia: W.B. Saunders Company, 1973.

3. Fischer E., cited by McCormick WF, Stewart JH. (1983) Ossification patterns of costal cartilage as an indicator of sex. Arch Pathol Lab Med 107, 206-10.

4. Horner JL. (1949) Premature calcification on the costal cartilage, its frequent association with symptoms of non organic origin. Amer J Med Sci 218, 186-93.

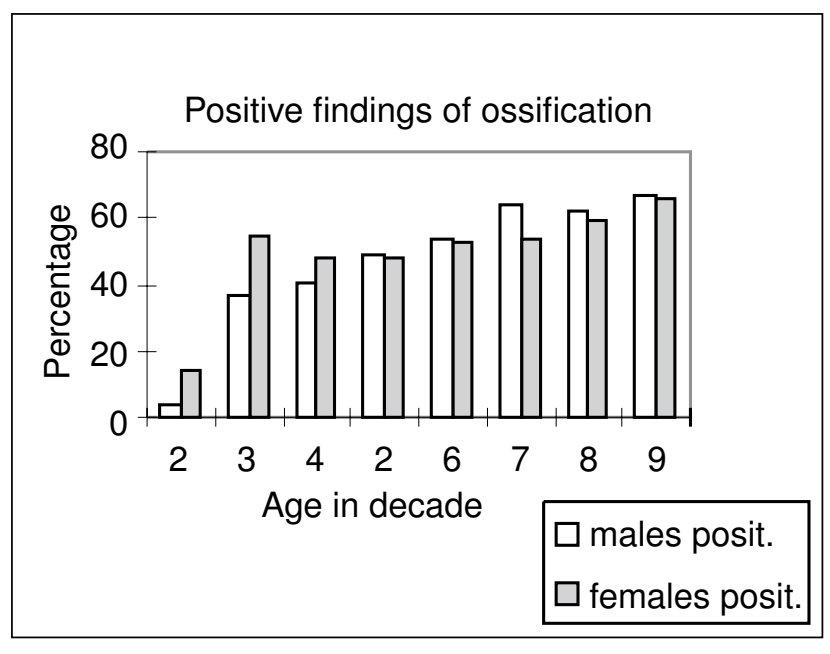

Fig. 5. The relationship between age and positive ossification findings in men and women.

5. Kampen WU, Claassen H, Kirsch T. (1995) Mineralization and osteogenesis in human first rib cartilage. Ann Anat 177, 177-77.

6. King JB. (1939) Calcification of the costal cartilage. Brit J Radiol 12, 2-12.

7. Navani S, Shah JR, Levy SP. (1970) Determination of sex by costal cartilage calcification. AJR Rad Ther 108(1,2), 771-74.

8. Nishino K. (1969) Studies on the human rib cartilage. Kekkaku 44, 131-37.

9. Vastine JH, Vastine MF (1948) Genetic influence on osseous development with particular reference to deposition of calcium in the costal cartilage. AJR Rad Ther 59, 213-21.

10. Verma GL, Agerwal GR, Hiran S. (1980) Sex determination by costal cartilage calcification. Ind J Rad 34, 22-25. 